\title{
Using News and Views Articles, Lab Reports, and Wiki Entries to Teach Students How to Read and Write for Diverse Scientific Audiences in an Introductory Biology Laboratory Course
}

\author{
Adam Jacobson \\ New York Medical College \\ 1403 Old Farm Road, Valhalla, NY 10595 \\ Tel: 1-561-339-3211Ｅ-mail: adam_jacobson@nymc.edu \\ Melissa S. Kosinski-Collins (Corresponding author) \\ Department of Biology, Brandeis University \\ 415 South Street, MS008, Waltham, MA 02454, United States \\ Tel: 1-781-736-3126_E-mail: kosinski@brandeis.edu
}

Received: February 16, 2012 Accepted: February 29, 2012 Published: May 1, 2012

doi:10.5296/jse.v2i2.1407ＵRL: http://dx.doi.org/10.5296/jse.v2i2.1407

\begin{abstract}
The ability to read and understand complicated scientific concepts poses a distinct challenge to students in large-enrollment introductory science courses. These students often have difficulty understanding that to be successful scientists, they must be able to relate findings to audiences of diverse backgrounds - those who may or may not have any formal training in the field. In order to increase the science literacy and knowledge of our students, we have created a three assignment series in our introductory biology laboratory course at Brandeis University that includes an encyclopedia entry, a news article for a multidiscipline science journal, and a formal peer-reviewed journal-style lab report. We have found that these assignments improved our students' writing skills and their confidence in their scientific writing ability.
\end{abstract}

Keywords: Science literacy, Science education, News articles 


\section{Introduction to Science Literacy}

Scientific literacy with respect to reading and writing has recently become the focus of many discussions centered on curriculum development and student engagement in the sciences. Teaching college students how to read and understand peer-reviewed scientific literature is an important step in the development of their scientific careers, although many students will not be exposed to these types of articles until they reach upper-level seminar courses in their junior or senior year. Furthermore, the American Association for the Advancement of Science has emphasized the importance of teaching scientific literacy for all students (not just those pursuing careers in science) in order to provide the tools that allow them to make informed decisions on scientific concepts presented in the media (1990).

In a recent review, van der Broek discusses how students read and absorb information from text in scientific classroom settings (2010). Stumbling blocks to student understanding in scientific literature may include the use of sophisticated academic language, brevity, and authoritative writing styles, in addition to more obvious conceptual knowledge gaps (Snow 2010). Often our students are expected to intuitively know "how to read" journal articles in upper-level undergraduate and graduate classes, without ever having been taught how to break down and interpret data and conclusions presented in this style. Many resources have been developed that help guide students when reading primary literature (Gillen 2007; Gross et al. 2002; Levine 2001; McNeal 2011).

In addition to formalized instruction on learning how to read science articles, students should also be given direction on science writing as well. Writing in science involves multiple levels of comprehension as well as the ability to synthesize and describe complicated concepts in an understandable way. Many resources exist to assist students in writing lab reports that model primary literature articles (McMillan 1997; Pechenik 2006, Knisely 2009). Using these texts, students learn how to incorporate their own novel data and translate it into the words of a professional scientist. Although useful, these exercises target advanced audiences and encourage the use of contextual jargon that may or may not be initially understood by the student author.

We have found that a higher level of scientific understanding emerges in our students when they are asked to explain information to both non-scientific and expert audiences. This "writing for understanding" approach has helped us re-envision our course. To increase the science literacy and knowledge of our students, we have created a three-assignment series in our introductory biology laboratory course at Brandeis University that includes an encyclopedia entry, a news article for a multidiscipline science journal, and a formal peer-reviewed journal-style lab report.

\section{University and Course Profile}

Brandeis is a private, liberal-arts university in Waltham, Massachusetts with an entering first-year class of about 800 students. Of the 800 students, more than half enter with the intention to pursue a career in the allied health professions. All of these students are required to complete the core sciences, including introductory chemistry, biology, organic chemistry, 
physics, and the accompanying laboratory courses.

Biol18a is an introductory level biology laboratory courses that accompanies the sophomore-level general biology lectures in genetics. The laboratory course is an independent entity complete with its own weekly one hour, twenty minute lecture and weekly four-hour laboratory sessions. Each semester, about 200 students enroll in the course; approximately two-thirds of these students intend on pursuing a career in a health related profession.

The weekly lectures of Biol18a are led by the course professor, while the laboratory is led by both a graduate and an undergraduate teaching assistant in sections of twenty-four students. Every week, students complete pre-lab and post-lab assignments and independently conduct a four hour experiment. Bio18a is taught in the spring semester and is considered a writing intensive course (WI), fulfilling one of the students three WI university graduation requirements. WI classes at Brandeis must meet the following five criteria:

- $\quad$ Require a significant amount of writing: 18-20 pages, 4,500-5,000 words

- $\quad$ Allow for revision based on instructor feedback

- $\quad$ Use writing for teaching as well as for evaluation

- Instruct students on how to carry out the writing assignments

- $\quad$ Include writing quality as a significant factor in the course grade

We developed and integrated our own resource for the writing and revising of journal-style lab reports into Biol18 (Treacy and Kosinski-Collins 2011). Although useful both for learning and evaluation of student progress in the course, based on their introduction sections, we found that students still had several shortcomings - they were not learning how to read and interpret primary literature articles and could not summarize results and conclusions from these types of articles in an understandable, cohesive way. After several iterations of the course, we further discovered that many our students were emerging with a deeper understanding of how to read and write primary literature, but were unaware of the importance of clear scientific communication with other non-biological audiences. Students matriculating from the course were able to formulate beginner-level journal articles for fellow molecular or cellular biologists, but did not grasp how science writing can be used to promote or explain experimental results to other individuals both inside and outside of the sciences.

In the spring of 2010, we developed additional writing assignments including an encyclopedia entry and a scientific news article to complement the formal lab reports assigned in Biol18a to help our students learn how to discuss biological data with diverse audiences and to increase their science literacy. We used pre- and post-writing samples and a formative assessment to determine student perception of learning gains on these assignments.

\section{Course Assignments}

\subsection{Initial Writing Sample}

On the first day of the semester, students were asked to write a one-page essay answering five 
basic questions about genetics as a discipline.
A. What is a model organism?
B. What is a genetic screen?
C. Give examples of model organisms that are used in genetic screens.
D. Why do we use model organisms in genetic screens?
E. Provide justification as to why scientists may select one over another.

Students answered the prompt without the use of any materials, other than their own knowledge.

The students were not graded on the factual accuracy of their responses, but rather on their writing style and proficiency in constructing a cohesive, understandable essay. This same assignment was also given on the last day of class, in order to assess the level of improvement in our students' writing skills and conceptual knowledge over the course of the semester. In order to maintain consistency, the same grader evaluated the student at the beginning and end of the semester, using a standardized rubric..

\subsection{Encyclopedia Entry}

A popular portion of Biol18a has been a series of dissections that students perform on one of nine different organisms (including crayfish, earthworm, marine clam, leopard frog, yellow perch, starfish, grasshopper, fetal pig, and squid). Students are asked to research the animal, its taxonomy, ecology, anatomy, methods of dissection, and then subsequently share their findings with their section. This has traditionally been accomplished through the use of an in-class presentation utilizing posters, Powerpoint presentations, etc. We developed a writing assignment instructing students to write a Wikipedia-style article about their assigned organism in addition to their formal presentation (Appendix A). Students were instructed to write their articles at a level so that a lay-person would be able to understand the material. Ideally, a well-written article could be used as a starting point for non-scientists seeking background information on the organism.

\subsection{Scientific News Article}

Biol18a students were presented with one of three published articles chosen based on medical relevance, and were instructed to write a paper in the style of a scientific journal-type news article, summarizing the details in a way that any general scientist would be able to comprehend (Appendix B). This assignment was extremely multifaceted and was approached in a stepwise manner as it involved reading comprehension of a complex journal entry, the necessity to distill salient information from said article, as well as the ability to explain the complex material in more simplistic terms.

Students were first asked to read the article highlighting the top ten things that were the most difficult to understand. They then discussed the "who, what, where, when and why's" of the paper with their TAs and classmates in section. The students then wrote multiple drafts of the 
scientific news article before finalizing the document.

\subsection{Peer Review-Style Lab Report}

Traditionally, undergraduate biology laboratory courses involved modular experiments that function independently from one another. Biol18a strives to incorporate all of the practical skills and techniques that are normally acquired through these means into a semester-long series of connected experiments. Specifically, in the Spring 2010, students conducted a four week long project utilizing an $S$. cerevisiae model to create temperature sensitive mutations in a uracil-production pathway.

The journal articles consisted of seven sections: title page, abstract, introduction, methods, results, discussion, and references, as described in Treacy \& Kosinski Collins (2010). These reports were written at a much higher level of detail than the previous assignments, allowing the students to explore yet another facet of science writing.

\subsection{Rewrite Process}

Students were given the opportunity to rewrite the encyclopedia entry and the scientific news article. This was done not only to reflect current practices in science writing, but also to allow the students to review their errors and learn from their mistakes. After a first draft was turned in, teaching assistants had one week to grade and annotate each assignment. The following week, the papers were returned, and students had one more week to revise the drafts. During this time, students are free to consult with the professor, their TAs, or the university-run writing center. Once returned, the assignments were graded according to the same criteria as were the first drafts, paying special attention to the specific changes students made based on initial feedback.

No opportunity was given for our students to rewrite the final lab report, because the class had already been exposed to a semester of lab reports in the fall semester of the course.

\section{Assessment of Writing and Student Learning Gains}

We periodically evaluated our students' writing and understanding of course material over the semester. We formally graded each of their writing assignments for both writing quality and understanding and administered an end-of-the-semester survey to the class that probed the students' assessment of the writing assignments. Responses were collected from 153 of the approximately 190 students enrolled in the course.

After completion of the course and its various writing assignments, most of students felt comfortable explaining biological concepts to a wide variety of audiences with $77 \%$ agreeing at some level (Table 1). Additionally, 79\% of our students felt they knew what is expected in a scientific paper, again showing the value of these activities. Through the initial writing sample assigned at both the beginning and end of the course, we additionally saw an overall improvement in our students' ability to write in terms of language, grammar, and clarity over the course of the semester as almost all students improved their scores by at least $16 \%$. 
Table 1. Student end of term evaluation question summary

\begin{tabular}{|l|l|l|l|l|l|l|l|l|}
\hline Question & $\mathbf{1}$ & $\mathbf{2}$ & $\mathbf{3}$ & $\mathbf{4}$ & $\mathbf{5}$ & $\mathbf{6}$ & $\mathbf{7}$ & Avg. \\
\hline $\begin{array}{l}\text { I feel confident in my ability to explain biological } \\
\text { concepts to a variety of audiences. }\end{array}$ & $2 \%$ & $5 \%$ & $3 \%$ & $13 \%$ & $22 \%$ & $34 \%$ & $21 \%$ & 5.34 \\
\hline I know what is expected as part of a scientific paper. & $4 \%$ & $3 \%$ & $6 \%$ & $8 \%$ & $21 \%$ & $33 \%$ & $35 \%$ & 5.38 \\
\hline
\end{tabular}

Percentage summaries of 153 student responses. Students were instructed to rank their answers on a 7 point scale where 1 indicated "strongly disagree", 4 indicated "neutral" and 7 indicated "strongly agree."

The incorporation of writing assignments targeted to different audiences has been value to our introductory biology students in both helping them connect complicated scientific concepts, improving their writing skills, and in improving their science literacy. This multi-assignment approach could be useful for students in introductory science courses in various disciplines, as it provides a venue through which the students must learn to distill and relate information to others in an understandable and approachable format.

\section{References}

American Association for the Advancement of Science. (1990). Science for All Americans: Project 2061. New York, Oxford University Press.

Gillen, C. (2007). Reading primary literature: A practical guide to evaluating research articles in biology. San Francisco, Benjamin Cummings.

Gross, A. G., Harmon, J. E., \& Reidy, M. (2002). Communicating Science. The scientific article from the 17th century to the present. New York, Oxford University Press.

Knisley, K. (2009). A student handbook for writing in biology. (3rd ed.) Sunderland, Sinauer Associates.

Levine, E. (2001) Reading your way to scientific literacy. Journal of College Science Teaching, 31, 122-125.

McMillan, V.E. (1997). Writing Papers in the Biological Sciences. New York, St. Martin's Press.

McNeal, A. (2011). How to Read a Scientific Research Paper-a four-step guide for students and for faculty. School of Natural Science, Hampshire College, Amherst MA, [Online] http://helios.hampshire.edu/ apmNS/design/RESOURCES/HOW_READ.html (August 1, 2011)

Pechenik, J. (2006). A short guide to writing about biology. ( $8^{\text {th }}$ ed.) Longman.

Snow, C. E. (2010). Academic language and the challenge of reading for learning about science. Science 328, 450-452. http://dx.doi.org/10.1126/science.1182597 


\section{Macrothink}

Treacy, D. J., \& Kosinski-Collins, M.S. (2011). Using the Writing and Revising of Journal Articles to Increase Science Literacy and Understanding in a Large Introductory Biology Laboratory Course. Atlas Journal of Science Education. 1, 29-37. http://dx.doi.org/10.5147/ajse.2011.0032

Van den Broek, P. (2010). Using texts in science education: cognitive processes and knowledge representations. Science 328, 453-456. http://dx.doi.org/10.1126/science.1182594

\section{Appendix A}

\section{Encyclopedia Entry}

Write an encyclopedia entry for the organism you were assigned to present in Lab 3.

Online Wiki informational sources like Wikipedia have recently become extremely popular resources for the acquisition of information of all types. Background on scientific topics such as viruses, organisms, and experiments can easily be found within these resources. For next week, write a two-paged Wikipedia entry for the class of organism you have selected as your dissection model. This article needs to be clear, concise and should be understandable to all general audiences including scientists and non-scientists alike.

1. You must include a reference section that utilizes at least 5 sources.

2. All references, figures, and text must fit within the two-page guideline.

3. Use 1 inch margins and no less than size 11 point font.

4. Please provide a hard-copy of your entry to your TA with a rubric attached.

5. Upload your assignment into the course LATTE page.

6. You do not need to write this in your notebook.

\section{Appendix B}

\section{Scientific News Article}

Although trained as a biological research scientist, because of the recession you have restarted your career as a science writer. You are now a journalist working for Proceedings of the Brandeis Academy of Biol18 writing for the "News" portion of the publication. In this section of the journal, exciting new discoveries in all scientific disciplines are described to scientists of all fields.

Specifically, your job is to describe research in biology to all scientists including physicists, chemists, computational biologists, etc.

Given the recent outbreak of H1N1 in the United States, the editors of $P B A B$ have asked you to write a "News" feature detailing the current research given in the article below. In addition, your editor suggests that you describe the etiology, symptoms, and molecular basis of this pandemic in your piece.

Week 1: Reading a Scientific Article 
A. Read the article assigned to your section.

a. In your notebook, write a bullet-point list with what you think are the 20 most important points of the paper. After reading the 20 points, a reader should be able to understand the purpose, procedure, results, and significance of the study.

b. Using a highlighter, mark all parts of the paper that you do not understand.

B. Discuss as a section your 20 “important points" in class.

a. Are there any common trends between the purposes of the paper between students?

b. What were the main techniques used by the authors and how do they work?

c. Does everyone agree on the overall significance of this paper both culturally and scientifically?

C. What aspects of the paper were hard for the group to understand? Speculate as why this is so. Determine whether or not these aspects of the paper are critical for understanding the data presented.

\section{Week 2: Writing a News Article}

Complete your article based on the paper you read. Be sure your article adheres to the following specific guidelines:

- $\quad$ All scientifically acceptable citations must have been published/posted in the last 12 months.

- $\quad$ You may utilize up 5 additional outside resources that should be cited as described in your Biol18a lab manual. These should not be included in your word count.

- $\quad$ The level of science presented must be understandable by all members of the $P B A B$ reading audience (all Brandeis undergraduate science majors).

- $\quad$ The article must adhere to the 1500 word limit enforced by the $P B A B$ editors. Note there is no minimum on this length.

- $\quad$ The article must have an "attention-grabbing” title.

- The article must include an appropriate "attention-grabbing” figure complete with a title and figure legend.

- $\quad$ Pay close attention to the style and tone used in the "News" examples provided. Note they are not written like conventional journal articles.

Week 4: Rewrite

Please rewrite your scientific news article paying careful attention to the rubric and to the comments made on your first draft by your TA. Your rewrite is due at 1:10 at the beginning of Lab 4. In order to receive credit for this assignment, you must include all of the following:

- $\quad$ The first graded draft of your News article 
- $\quad$ The original graded rubric for your article

- $\quad$ Your second rewritten News article

- $\quad$ A copy of your bullet-point list from Lab 1

- $\quad$ A blank rubric

- $\quad$ A brief reflection answering each of the following self-refection questions:

A. On a scale of 1 to 7 (1 indicating easy, 7 indicating extremely difficult) how hard was this paper for you to understand?

B. Which aspect of your paper do you think improved the most between drafts? Which aspect improved the least? Why?

C. Do you think a physicist would understand your News article? Why or why not?

D. Did you enjoy this assignment? Why or why not? 